\title{
S100A14 rs11548103 G>A polymorphism is associated with a decreased risk of esophageal cancer in a Chinese population
}

\author{
Yang Zhao ${ }^{1, *}$, Feng Yao ${ }^{1, *}$, Weifeng Tang ${ }^{2}$, Haiyong $\mathbf{G u}^{1}$ and Heng Zhao ${ }^{1}$ \\ ${ }^{1}$ Department of Thoracic Surgery, Shanghai Chest Hospital, Shanghai Jiaotong University, Shanghai, China \\ ${ }^{2}$ Department of Cardiothoracic Surgery, Affiliated People's Hospital of Jiangsu University, Zhenjiang, Jiangsu Province, China \\ *Joint first author \\ Correspondence to: Haiyong Gu, email: haiyong_gu@hotmail.com \\ Heng Zhao, email: h_zhao28@163.com \\ Keywords: S100A14, polymorphisms, esophageal cancer, molecular epidemiology
}

Received: December 19, $2016 \quad$ Accepted: July 30, $2017 \quad$ Published: September 14, 2017

Copyright: Zhao et al. This is an open-access article distributed under the terms of the Creative Commons Attribution License 3.0 (CC BY 3.0), which permits unrestricted use, distribution, and reproduction in any medium, provided the original author and source are credited.

\section{ABSTRACT}

Objective: In China in 2009, esophageal cancer was the fifth most commonly diagnosed malignancy and the fourth leading cause of malignancy-related death. Accumulating evidence indicates that genetic factors might play an important role in esophageal squamous cell carcinoma (ESCC) carcinogenesis.

Materials and Methods: In total, we recruited 629 ESCC patients and 686 controls. Genetic variations in the S100A14, MLH1, SMAD7 and CCL22/MDC genes were measured using the ligation detection reaction method.

Results: When the S100A14 rs11548103 GG genotype was considered as the reference group, the GA genotype associated with decreased risk of ESCC (GA vs. GG: adjusted $\mathrm{OR}=0.73,95 \% \mathrm{CI}=0.57-0.93, p=0.009)$. In the dominant model, GA/AA variants were associated with a significantly decreased risk of ESCC compared with the GG genotype (GA/AA vs. GG: adjusted $\mathrm{OR}=0.76,95 \% \mathrm{CI}=0.61-0.95$, $p=0.018$ ). Logistic regression analyses showed that the MLH1 rs1800734 C>T, SMAD7 rs12953717 C>T and CCL22/MDC rs4359426C>A polymorphisms were not associated with the risk of ESCC in any of the models tested.

Conclusions: Our findings indicated that, in a Chinese population, rs11548103 might contribute to a decreased risk of ESCC. Further studies are need to confirm these data with results from a lager cohort and different ethnic origins.

\section{INTRODUCTION}

In China in 2009, esophageal cancer (EC) was the fourth leading cause of cancer death and the fifth most common diagnosed malignancy [1]. Esophageal squamous cell carcinoma (ESCC) accounts for more than $90 \%$ of EC cases. Single nucleotide polymorphisms (SNPs), as individual genetic risk factors, might play a vital role in ESCC carcinogenesis in addition to certain environmental risk factors [2].

S100A14 is located on chromosome 1q21 and is one of the least-characterized members of theS100 family [3]. S100A14 is a low molecular weight calcium-binding protein $[3,4]$. Since loss of expression or overexpression of S100A14 has been reported in tumors, its functional role has been proposed to be organ-specific and involved in tumorigenesis [5]. S100A14 is also a target for p53 and could alter p53 transactivity and stability, and by regulating matrix metalloproteinase (MMP)2 transcription, S100A14 affects cell invasiveness in a p53-dependent manner [6].

S100 proteins take part in the process of terminal differentiation of the human epidermis [7] and have been implicated in cancer, as altered expression levels of some S100 proteins have been identified to correlate with tumor differentiation, including in ESCC. It has recently been reported that the S100 family member S100A14 plays a role in driving esophageal carcinogenesis, showing that 
extracellular S100A14 may affect EC cell proliferation and/or apoptosis via interaction with the receptor for advanced glycation end-products (RAGE) [8]. S100A14 can also regulate oral squamous cell carcinoma cell by modulating the expression of MMP1 and MMP9 [9]. One genetic variant of $S 100 \mathrm{~A} 14$ (461G $>$ A, rs 11548103$)$ is located in the $5^{\prime}$-untranslated region (UTR) and has been shown to disrupt a p53-binding site. This variant is correlated with decreased expression of $S 100 \mathrm{A14}$ both in vitro and in vivo in target tissues. Additionally, a previous study reported that rs11548103-A was associated with risk for ESCC [10].

MutL homolog 1 (MLH1) is a member of the DNA mismatch repair (MMR) genes, which encode several highly conserved proteins. Deficiency in MMR may play important roles in the etiology of cancer. The rs1800734 (-93G/A) polymorphism in MLH1 is located in the promoter region, which is responsible for the transcriptional activity of this gene.

SMAD7, an inhibitory SMAD, is a negative regulator of the transforming growth factor-beta (TGF- $\beta$ ) signaling pathway, which promotes the anti-inflammatory roles of TGF- $\beta$ signaling via binding to the TGF- $\beta$ activated kinase (TAK)1-binding proteins that inhibit TAK1, TAB2 and TAB3 [11, 12]. The rs12953717-T allele at $S M A D 7$ has been associated with increased susceptibility to colorectal cancer (CRC) among both Caucasians and Asians [13].

Macrophage-derived chemokine (MDC), also known as C-C motif chemokine 22 (CCL22), is a chemokine secreted mainly by macrophages [14]. Rs4359426, a variant of CCL22, has been shown to associate with overexpression of CCL22 mRNA and susceptibility to atopic dermatitis in a gain-of-function manner [15].

Genetic variants in $S 100 A 14$ (rs11548103G $>A$ ), MLH1 (rs1800734 C>T), SMAD7 (rs12953717C $>\mathrm{T})$ and $C C L 22 / M D C$ (rs4359426C>A) may contribute to the etiology of ESCC. In a hospital-based case-control study including 629 ESCC cases and 686 controls, we performed genotyping and tested the association of these four functional SNPs with ESCC in a Chinese population.

\section{RESULTS}

\section{Characteristics of the study population}

Characteristics of the ESCC cases and controls are summarized in Table 1. According to $\chi^{2}$ tests, the ESCC cases and controls were adequately matched for age and sex. Meanwhile, we found significant differences in smoking and drinking status between the ESCC cases and controls. Table 2 presents information on S100A14 rs11548103G $>$ A, MLH1 rs1800734 C $>$ T, SMAD7 rs $12953717 \mathrm{C}>\mathrm{T}$ and $C C L 22 / M D C$ rs4359426 C $>\mathrm{A}$. For these four genotyped SNPs, in our controls, the minor allele frequency (MAF) was very similar to the MAF for
Chinese in database. Furthermore, in controls, goodnessof-fit $\chi^{2}$ tests indicated that the observed genotype frequencies were all in Hardy-Weinberg equilibrium (HWE) for these polymorphisms (Table 2).

\section{Association between rs11548103, rs1800734, rs12953717 and rs4359426 and risk of ESCC}

As shown in Table 3, the GG, GA and AA allele frequencies of rs 11548103 were $51.2,37.8$ and $10.9 \%$, respectively, in the ESCC group and 45.5, 44.3 and $10.2 \%$, respectively, in the healthy control group. When the GG genotype was adopted as the reference group, the GA genotype significantly decreased the risk of ESCC (GA vs. GG: adjusted $\mathrm{OR}=0.73,95 \% \mathrm{CI}=0.57-0.93$, $p=0.009$ ). In the dominant model, we also found that carriers of the GA/AA variants had a decreased risk of ESCC compared with carriers of the GG genotype (GA/ AA vs. GG: adjusted OR $=0.76,95 \% \mathrm{CI}=0.61-0.95$, $p=0.018$ ) (Table 3).

Logistic regression analyses indicated that rs1800734, rs12953717 and rs4359426 were not associated with the risk of ESCC in any of the models (Table 3 ).

\section{Stratification analyses on rs11548103}

To evaluate the effects of rs 11548103 on ESCC risk according to different age groups, sex, tobacco consumption and drinking status, we performed stratification analyses. A significantly decreased risk of ESCC associated with rs 11548103 was evident among younger patients (GA vs. GG: adjusted $\mathrm{OR}=0.69,95 \%$ $\mathrm{CI}=0.49-0.98, p=0.038)$, male patients (GA/AA vs. GG: adjusted $\mathrm{OR}=0.70,95 \% \mathrm{CI}=0.53-0.92, p=0.012$ ) and patients who never drink (GA/AA vs. GG: adjusted $\mathrm{OR}=0.72,95 \% \mathrm{CI}=0.55-0.94, p=0.017$ ) or smoke (GA/AA vs. GG: adjusted OR $=0.72,95 \% \mathrm{CI}=0.54$ $0.96, p=0.025)$ (Table 4).

\section{DISCUSSION}

In the present hospital-based case-control study of ESCC, we identified that rs 11548103 was associated with decreased risk of ESCC.

Accumulating evidence has demonstrated the importance of the S100 family in cell migration, invasion and cancer metastasis [6]. S100A14, a member of the S100 family, is involved in several vital functional and pathological processes [16]. Additionally, it is predicted to be under tight transcriptional and post-translational regulation [16]. A previous phylogenetic investigation of the S100 family indicated that S100A14 is different from the other members of the S100 family (except S100A13) due to alterations in several key amino acid residues, which are responsible for the binding of calcium, suggesting that the activity of the S100A14 protein is 
Table 1: Distribution of selected demographic variables and risk factors in ESCC cases and controls

\begin{tabular}{cccccc}
\hline \multirow{2}{*}{ Variable } & \multicolumn{2}{c}{ Cases $(\boldsymbol{n}=\mathbf{6 2 9})$} & \multicolumn{2}{c}{ Controls $(\boldsymbol{n}=\mathbf{6 8 6})$} & \multirow{2}{*}{$\boldsymbol{p}^{\mathbf{a}}$} \\
\cline { 2 - 5 } & $\boldsymbol{n}$ & $\mathbf{\%}$ & $\boldsymbol{n}$ & $\mathbf{\%}$ & \\
\hline Age (years) mean \pm SD & \multicolumn{2}{c}{$62.85( \pm 8.13)$} & $62.58( \pm 7.89)$ & & 0.541 \\
Age (years) & & & & 0.155 \\
$<63$ & 310 & 49.28 & 365 & 53.21 & \\
$\geq 63$ & 319 & 50.72 & 321 & 46.79 & \\
Sex & & & & 0.185 \\
Male & 444 & 70.59 & 461 & 67.20 & \\
Female & 185 & 29.41 & 285 & 32.80 & \\
Tobacco use & & & & \\
Never & 355 & 56.44 & 499 & 72.74 & \\
Ever & 274 & 43.56 & 187 & 27.26 & \\
Alcohol use & & & & & \\
Never & 428 & 68.04 & 526 & 76.68 & \\
Ever & 201 & 31.96 & 160 & 23.32 & \\
\hline
\end{tabular}

${ }^{a}$ Two-sided $\chi^{2}$ test and student $t$ test; Bold values are statistically significant $(p<0.05)$.

Table 2: Primary information for $S 100 A 14$ rs11548103 G>A, MLH1 rs1800734 C $>$ T, SMAD7 rs12953717 $\mathrm{C}>\mathrm{T}$ and $C C L 22 / M D C$ rs4359426 $\mathrm{C}>\mathrm{A}$ polymorphisms

\begin{tabular}{|c|c|c|c|c|}
\hline Genotyped SNPs & $\begin{array}{c}\text { S100A14 } \\
\text { rs11548103 G>A }\end{array}$ & $\begin{array}{c}\text { MLH1rs1800734 } \\
\text { C }>\text { T }\end{array}$ & $\begin{array}{c}\text { SMAD7rs12953717 } \\
\text { C }>\text { T }\end{array}$ & $\begin{array}{c}\text { CCL22/ } \\
\text { MDCrs4359426C }>A \\
\end{array}$ \\
\hline Chromosome & Chr1 & Chr3 & Chr18 & Chr16 \\
\hline Function & UTR-5 & UTR-5 & Intron & missense \\
\hline $\begin{array}{c}\text { Chr Pos } \\
\text { (Genome Build 36.3) }\end{array}$ & 151854964 & 37009950 & 44707927 & 55950234 \\
\hline Regulome DB Score ${ }^{\mathrm{a}}$ & 5 & 4 & 5 & 4 \\
\hline TFBS $^{\mathrm{b}}$ & Y & $\mathrm{Y}$ & - & - \\
\hline Splicing(ESE or ESS) & Y & - & - & Y \\
\hline miRNA(miRanda) & - & - & - & - \\
\hline nsSNP & - & - & - & Y \\
\hline $\mathrm{MAF}^{\mathrm{c}}$ for Chinese in database & 0.333 & 0.415 & 0.183 & 0.136 \\
\hline MAF in our controls $(n=686)$ & 0.323 & 0.416 & 0.206 & 0.149 \\
\hline $\begin{array}{l}p \text { value for HWE } \mathrm{HW}^{\mathrm{d}} \\
\text { test in our controls }\end{array}$ & 0.741 & 0.944 & 0.889 & 0.520 \\
\hline Genotyping method ${ }^{\mathrm{e}}$ & LDR & LDR & LDR & LDR \\
\hline$\%$ Genotyping value & $95.29 \%$ & $96.43 \%$ & $95.13 \%$ & $98.63 \%$ \\
\hline
\end{tabular}

${ }^{a}$ http://www.regulomedb.org/.

${ }^{\mathrm{b}}$ TFBS:transcription factor binding site (http://snpinfo.niehs.nih.gov/snpinfo/snpfunc.htm).

'MAF: minor allele frequency, S100A14 rs11548103 G>A MAF is in CHB+JPT population.

${ }^{\mathrm{d}}$ HWE: Hardy-Weinberg equilibrium.

${ }^{\mathrm{e}} \mathrm{LDR}$ : ligation detection reaction. 
Table 3: Logistic regression analyses of associations between $S 100 A 14 \operatorname{rs11548103} \mathrm{G}>\mathrm{A}, \mathrm{MLH}$ rs1800734 C>T, SMAD7 rs12953717 C $>$ T and $C C L 22 / M D C$ rs4359426 C $>A$ polymorphisms and risk of ESCC

\begin{tabular}{|c|c|c|c|c|c|c|c|c|}
\hline \multirow[t]{2}{*}{ Genotype } & \multicolumn{2}{|c|}{$\begin{array}{c}\text { Cases } \\
(n=629)\end{array}$} & \multicolumn{2}{|c|}{$\begin{array}{l}\text { Controls } \\
(n=686)\end{array}$} & \multirow{2}{*}{$\begin{array}{l}\text { Crude OR } \\
(95 \% \text { CI) }\end{array}$} & \multirow{2}{*}{$p$} & \multirow{2}{*}{$\begin{array}{l}\text { Adjusted OR } \\
\quad(95 \% \text { CI) }\end{array}$} & \multirow[t]{2}{*}{$p$} \\
\hline & $n$ & $\%$ & $n$ & $\%$ & & & & \\
\hline \multicolumn{9}{|l|}{$\begin{array}{c}\text { S100A14 rs11548103 } \\
\text { G }>A\end{array}$} \\
\hline GG & 309 & 51.2 & 296 & 45.5 & 1.00 & & 1.00 & \\
\hline GA & 228 & 37.8 & 288 & 44.3 & $0.76(0.60-0.96)$ & 0.022 & $0.73(0.57-0.93)$ & 0.009 \\
\hline AA & 66 & 10.9 & 66 & 10.2 & $0.96(0.66-1.40)$ & 0.823 & $0.90(0.61-1.33)$ & 0.597 \\
\hline AA vs.GA vs.GG & & & & & & & & 0.064 \\
\hline $\mathrm{GA}+\mathrm{AA}$ & 294 & 48.8 & 354 & 54.5 & $0.80(0.64-0.99)$ & 0.044 & $0.76(0.61-0.95)$ & 0.018 \\
\hline $\mathrm{GG}+\mathrm{GA}$ & 537 & 89.1 & 584 & 89.8 & 1.00 & & 1.00 & \\
\hline AA & 66 & 10.9 & 66 & 10.2 & $1.09(0.76-1.56)$ & 0.648 & $1.04(0.72-1.51)$ & 0.819 \\
\hline $\mathrm{G}$ allele & 846 & 70.1 & 880 & 67.7 & 1.00 & & & \\
\hline A allele & 360 & 29.9 & 420 & 32.3 & $0.89(0.75-1.06)$ & 0.185 & & \\
\hline \multicolumn{9}{|l|}{$\begin{array}{c}M L H 1 \\
\text { rs } 1800734 \mathrm{~A}>\mathrm{G}\end{array}$} \\
\hline AA & 207 & 33.9 & 224 & 34.1 & 1.00 & & 1.00 & \\
\hline AG & 291 & 47.6 & 320 & 48.7 & $0.98(0.77-1.26)$ & 0.899 & $0.92(0.72-1.18)$ & 0.518 \\
\hline GG & 113 & 18.5 & 113 & 17.2 & $1.08(0.78-1.49)$ & 0.631 & $1.03(0.74-1.43)$ & 0.849 \\
\hline GG vs.AG vs.AA & & & & & & & & 0.827 \\
\hline $\mathrm{AG}+\mathrm{GG}$ & 404 & 66.1 & 433 & 65.9 & $1.01(0.80-1.27)$ & 0.936 & $0.95(0.75-1.20)$ & 0.668 \\
\hline $\mathrm{AA}+\mathrm{AG}$ & 498 & 81.5 & 544 & 82.8 & 1.00 & & 1.00 & \\
\hline GG & 113 & 18.5 & 113 & 17.2 & $1.09(0.82-1.46)$ & 0.547 & $1.08(0.81-1.45)$ & 0.589 \\
\hline A allele & 705 & 57.7 & 768 & 58.4 & 1.00 & & & \\
\hline G allele & 517 & 42.3 & 546 & 41.6 & $1.03(0.88-1.21)$ & 0.700 & & \\
\hline \multicolumn{9}{|c|}{$S M A D 7$ rs $12953717 \mathrm{C}>\mathrm{T}$} \\
\hline $\mathrm{CC}$ & 355 & 59.2 & 410 & 63.0 & 1.00 & & 1.00 & \\
\hline $\mathrm{CT}$ & 212 & 35.3 & 214 & 32.9 & $1.14(0.90-1.45)$ & 0.266 & $1.19(0.93-1.51)$ & 0.162 \\
\hline $\mathrm{TT}$ & 33 & 5.5 & 27 & 4.1 & $1.41(0.83-2.39)$ & 0.201 & $1.37(0.80-2.34)$ & 0.255 \\
\hline TT vs.CT vs.CC & & & & & & & & 0.288 \\
\hline $\mathrm{CT}+\mathrm{TT}$ & 245 & 40.8 & 241 & 37.0 & $1.17(0.94-1.47)$ & 0.167 & $1.21(0.96-1.53)$ & 0.109 \\
\hline $\mathrm{CC}+\mathrm{CT}$ & 567 & 94.5 & 624 & 95.9 & 1.00 & & 1.00 & \\
\hline $\mathrm{TT}$ & 33 & 5.5 & 27 & 4.1 & $1.35(0.80-2.27)$ & 0.265 & $1.29(0.76-2.19)$ & 0.353 \\
\hline $\mathrm{C}$ allele & 922 & 76.8 & 1034 & 79.4 & 1.00 & & & \\
\hline T allele & 278 & 23.2 & 268 & 20.6 & $1.16(0.96-1.41)$ & 0.118 & & \\
\hline \multicolumn{9}{|l|}{$\begin{array}{c}C C L 22 / \\
M D C \mathrm{rs} 4359426 \mathrm{C}>\mathrm{A}\end{array}$} \\
\hline $\mathrm{CC}$ & 461 & 74.8 & 491 & 72.1 & 1.00 & & 1.00 & \\
\hline CA & 138 & 22.4 & 177 & 26.0 & $0.83(0.64-1.07)$ & 0.155 & $0.86(0.66-1.12)$ & 0.254 \\
\hline AA & 17 & 2.8 & 13 & 1.9 & $1.39(0.67-2.90)$ & 0.376 & $1.38(0.65-2.91)$ & 0.398 \\
\hline AA vs.CA vs.CC & & & & & & & & 0.217 \\
\hline $\mathrm{CA}+\mathrm{AA}$ & 155 & 25.2 & 190 & 27.9 & $0.87(0.68-1.11)$ & 0.265 & $0.90(0.70-1.15)$ & 0.391 \\
\hline $\mathrm{CC}+\mathrm{CA}$ & 599 & 97.2 & 668 & 98.1 & 1.00 & & 1.00 & \\
\hline AA & 17 & 2.8 & 13 & 1.9 & $1.46(0.70-3.03)$ & 0.312 & $1.43(0.68-3.01)$ & 0.343 \\
\hline $\mathrm{C}$ allele & 1060 & 86.0 & 1159 & 85.1 & 1.00 & & & \\
\hline A allele & 172 & 14.0 & 203 & 14.9 & $0.93(0.74-1.15)$ & 0.496 & & \\
\hline
\end{tabular}

\footnotetext{
${ }^{a}$ Adjusted for age, sex, smoking and drinking status; Bold values are statistically significant $(p<0.05)$.
} 
Table 4: Stratified analyses between $S 100 A 14$ rs11548103 G>A polymorphism and ESCC risk by sex, age, smoking status and alcohol consumption

\begin{tabular}{|c|c|c|c|c|c|c|c|c|c|}
\hline \multirow{2}{*}{ Variable } & \multicolumn{4}{|c|}{ S100A14 rs11548103 G $>$ A(case/control) a } & \multicolumn{5}{|c|}{ Adjusted OR b (95\%CI); p; phe } \\
\hline & GG & GA & $\mathbf{A A}$ & $\mathbf{G A}+\mathbf{A A}$ & GG & GA & AA & $\mathbf{G A}+\mathbf{A A}$ & AA vs. (GA + GG) \\
\hline \multicolumn{10}{|l|}{ Sex } \\
\hline Male & $221 / 194$ & $159 / 200$ & $47 / 42$ & $206 / 242$ & 1.00 & $\begin{array}{l}\mathbf{0 . 6 6}(\mathbf{0 . 4 9}-\mathbf{0 . 8 8}) \\
p: 0.005 ; p_{\mathrm{h}}: 0.311\end{array}$ & $\begin{array}{l}0.90(0.56-1.44) \\
p: 0.659 ; p_{\mathrm{h}}: 0.869\end{array}$ & $\begin{array}{l}\mathbf{0 . 7 0}(\mathbf{0 . 5 3}-\mathbf{0 . 9 2}) \\
p: 0.012 ; p_{\mathrm{h}}: 0.420\end{array}$ & $\begin{array}{l}1.09(0.70-1.72) \\
p: 0.699 ; p_{\mathrm{h}}: 0.628\end{array}$ \\
\hline Female & $88 / 102$ & $69 / 88$ & $19 / 24$ & $88 / 112$ & 1.00 & $\begin{array}{c}0.88(0.57-1.35) \\
p: 0.559 ; p_{\mathrm{h}}: 0.311\end{array}$ & $\begin{array}{l}0.92(0.47-1.81) \\
p: 0.808 ; p_{\mathrm{h}}: 0.869\end{array}$ & $\begin{array}{l}0.89(0.59-1.33) \\
p: 0.565 ; p_{\mathrm{h}}: 0.420\end{array}$ & $\begin{array}{l}0.97(0.51-1.86) ; \\
p: 0.937 ; p_{\mathrm{h}}: 0.628\end{array}$ \\
\hline \multicolumn{10}{|l|}{ Age } \\
\hline$<63$ & $154 / 155$ & $110 / 149$ & $34 / 40$ & $144 / 189$ & 1.00 & $\begin{array}{c}\text { 0.69 (0.49-0.98); } \\
p: 0.038 ; p_{\mathrm{h}}: 0.873\end{array}$ & $\begin{array}{l}0.85(0.50-1.43) \\
p: 0.532 ; p_{\mathrm{h}}: 0.488\end{array}$ & $\begin{array}{l}0.73(0.53-1.00) \\
p: 0.051 ; p_{\mathrm{h}}: 0.739\end{array}$ & $\begin{array}{l}1.00(0.60-1.65) \\
p: 0.989 ; p_{\mathrm{h}}: 0.494\end{array}$ \\
\hline$\geq 63$ & $155 / 141$ & $118 / 139$ & $32 / 26$ & $150 / 165$ & 1.00 & $\begin{array}{l}0.76(0.54-1.06) \\
p: 0.104 ; p_{\mathrm{h}}: 0.873\end{array}$ & $\begin{array}{l}0.97(0.55-1.74) \\
p: 0.929 ; p_{\mathrm{h}}: 0.488\end{array}$ & $\begin{array}{l}0.79(0.57-1.09) \\
p: 0.152 ; p_{\mathrm{h}}: 0.739\end{array}$ & $\begin{array}{l}1.11(0.64-1.94) \\
p: 0.708 ; p_{\mathrm{h}}: 0.494\end{array}$ \\
\hline \multicolumn{10}{|l|}{ Smoking status } \\
\hline Never & $186 / 219$ & $119 / 206$ & $34 / 46$ & $153 / 252$ & 1.00 & $\begin{array}{l}\mathbf{0 . 6 8}(\mathbf{0 . 5 0 - 0 . 9 2 )} \\
p: 0.012 ; p_{\mathrm{h}}: 0.431\end{array}$ & $\begin{array}{l}0.92(0.56-1.50) \\
p: 0.732 ; p_{\mathrm{h}}: 0.728\end{array}$ & $\begin{array}{c}0.72(0.54-0.96) \\
p: 0.025 ; p_{\mathrm{h}}: 0.429\end{array}$ & $\begin{array}{l}1.09(0.68-1.75) \\
p: 0.730 ; p_{\mathrm{h}}: 0.871\end{array}$ \\
\hline Ever & $123 / 77$ & $109 / 82$ & $32 / 20$ & $141 / 102$ & 1.00 & $\begin{array}{l}0.84(0.56-1.27) \\
p: 0.412 ; p_{\mathrm{h}}: 0.431\end{array}$ & $\begin{array}{l}0.97(0.51-1.85) \\
p: 0.932 ; p_{\mathrm{h}}: 0.728\end{array}$ & $\begin{array}{l}0.87(0.59-1.28) \\
p: 0.475 ; p_{\mathrm{h}}: 0.429\end{array}$ & $\begin{array}{l}1.06(0.58-1.95) \\
p: 0.853 ; p_{\mathrm{h}}: 0.871\end{array}$ \\
\hline \multicolumn{10}{|l|}{ Alcoholconsumption } \\
\hline Never & $217 / 229$ & $145 / 220$ & $47 / 48$ & $192 / 268$ & 1.00 & $\begin{array}{l}\mathbf{0 . 6 6}(\mathbf{0 . 5 0}-\mathbf{0 . 8 9}) \\
p: \mathbf{0 . 0 0 6} ; p_{\mathrm{h}}: 0.364\end{array}$ & $\begin{array}{l}0.97(0.61-1.55) \\
p: 0.907 ; p_{\mathrm{h}}: 0.492\end{array}$ & $\begin{array}{c}0.72(0.55-0.94) \\
p: 0.017 ; p_{\mathrm{h}}: 0.602\end{array}$ & $\begin{array}{l}1.17(0.75-1.82) \\
p: 0.498 ; p_{\mathrm{h}}: 0.330\end{array}$ \\
\hline Ever & $92 / 67$ & $83 / 68$ & $19 / 18$ & $102 / 86$ & 1.00 & $\begin{array}{l}0.93(0.59-1.47) \\
p: 0.747 ; p_{\mathrm{h}}: 0.364\end{array}$ & $\begin{array}{l}0.80(0.38-1.67) \\
p: 0.551 ; p_{\mathrm{h}}: 0.492\end{array}$ & $\begin{array}{l}0.90(0.58-1.39) \\
p: 0.638 ; p_{\mathrm{h}}: 0.602\end{array}$ & $\begin{array}{l}0.83(0.41-1.67) \\
p: 0.601 ; p_{\mathrm{h}}: 0.330\end{array}$ \\
\hline
\end{tabular}

${ }^{a}$ The genotyping was successful in 603 (95.9\%) ESCC cases, and $650(94.8 \%)$ controls for S100A14 rs $11548103 \mathrm{G}>\mathrm{A}$

b Adjusted for age, sex, smoking status and alcohol consumption (besides stratified factors accordingly) in a logistic regression model.

${ }^{c} p$ for heterogeneity.

independent of calcium [5]. In addition, functional studies have reported that S100A14 induces cell cycle arrest or apoptosis in ESCC $[8,10]$ and regulates the cell cycle in a p53- or RAGE-dependent manner.

Chen et al. reported that high levels of S100A14 associated significantly with elevated levels of MMP2 in clinical breast cancer samples with wild-type p53, but not in those with mutant p53 [5]. Although the function of S100A14 in breast cancer remains to be elucidated, it has been suggested that S100A14 binds HER2 and modulates its phosphorylation, leading to HER2stimulated cell proliferation, indicating that S100A14 may be a functional partner of HER2 in HER2-positive breast tumors [5]. Decreased expression of S100A14 with its genetic variant may be associated with an undifferentiated phenotype and poor prognosis in gastric cancer [17]. In a previous study, rs11548103was demonstrated to diminish a p53-binding site and was correlated with decreased expression of S100A14 both in vitro and in vivo in target tissues [10]. Furthermore, a case-control analysis showed that the $S 100 A 14$ rs11548103-A allele was associated with susceptibility to ESCC among smokers [10]. However, in our research, we found a protective effect of rs 11548103 . Additionally, rs11548103 appears to be a functional locus according to a SNP functional prediction website (http:// snpinfo.niehs.nih.gov/snpinfo/snpfunc.htm). However, the etiology of rs11548103 is not clearly known and requires further investigation.

Using the Power and Sample Size Calculation program (PS, version 3.0, 2009, http://biostat.mc.vanderbilt. edu/twiki/bin/view/Main/PowerSampleSize), with $\alpha=0.05$, the power of our analysis was 0.597 to detect an effect with an adjusted OR of 0.76 in 603 ESCC cases and 650 noncancer controls.

In this case-control study, there were several limitations. First, the ESCC patients and non-cancer controls were enrolled from local hospitals, where inherent bias may have occurred. Second, the polymorphisms we studied do not provide an extensive view of the genetic variability present. In the future, fine-mapping studies are required. Third, because of the limited sample size and absence of a validation cohort, the statistical power of our study was limited. Fourth, we did not obtain detailed cancer metastasis and survival information, which further restricted the analysis of $S 100 A 14$ rs $11548103 \mathrm{G}>\mathrm{A}$ polymorphism in ESCC progression and prognosis. The actual power might have decreased considerably upon stratification because of the very small sample numbers. Finally, in vitro or tissue-specific biological characterizations are required to confirm the current preliminary findings.

In conclusion, our study found that rs 11548103 may decrease the risk of ESCC. Tissue-specific biological characterization and a replication study with larger populations are required to confirm our findings.

\section{MATERIALS AND METHODS}

\section{Ethical approval of the study protocol}

We complied with the World Medical Association Declaration of Helsinki regarding ethical conduct of research involving human subjects and/or animals. The review board of Jiangsu University (Zhenjiang, China) 
approved the present case-control study. Written informed consent was provided by all participants.

\section{ESCC patients and controls}

From two affiliated hospitals (the Affiliated People's Hospital and the Affiliated Hospital of Zhenjiang, China), between October 2008 and December 2010, 629 cases with ESCC were recruited consecutively. All cases of ESCC were diagnosed by pathological analyses. Patients who previously had a history of malignancy or any metastasized cancer treated with radiotherapy or chemotherapy were excluded. For the control group, 686 non-cancer patients were matched to the ESCC cases with regard to age ( \pm 5 years) and sex. The controls were recruited during the same time period from the two affiliated hospitals of Jiangsu University. Most of the noncancer controls were being treated for trauma.

Using a pre-tested questionnaire, two trained interviewers questioned each participant personally. The demographic data information (e.g., age, sex) and ESCC-related risk factors (such as smoking and alcohol consumption) were obtained.

\section{Isolation of DNA and genotyping by ligation detection reaction (LDR)}

According to the manufacturer's protocol, genomic DNA was isolated from whole blood [18]. With technical support from the Biotechnology Company (Biowing Biotechnologies Inc., Shanghai, China), the DNA samples were genotyped using the PCR-LDR method [19]. One hundred sixty (12.17\%) were randomly selected for quality control checks and the reproducibility was $100 \%$.

\section{Statistical analyses}

Using $\chi^{2}$ statistical tests, we tested whether there were differences between cases and controls in the distributions of demographic characteristics (age and sex), selected variables (smoking and alcohol consumption), and the rs11548103, rs1800734, rs12953717 and rs4359426 genotypes. Using logistic regression analyses, the relationship of these four SNPs with risk of ESCC was assessed in terms of crude ORs and ORs adjusted for age, sex and smoking and alcohol consumption. HWE was tested by a goodness-of-fit $\chi^{2}$ test among the control subjects. All statistical analyses were performed with SAS 9.1.3 (SAS Institute, Cary, NC, USA).

\section{Abbreviations}

linkage disequilibrium, LD; odds ratio, OR; confidential interval, CI; single nucleotide polymorphisms, SNPs; esophageal squamous cell carcinoma, ESCC.

\section{ACKNOWLEDGMENTS}

We appreciate all the patients who participated in this study. We wish to thank Dr. Yiqun Chen (Biowing Applied Biotechnology Company, Shanghai, China) for technical support.

\section{CONFLICTS OF INTEREST}

The authors declare that there are no conflicts of interest.

\section{REFERENCES}

1. Chen W, He Y, Zheng R, Zhang S, Zeng H, Zou X, He J. Esophageal cancer incidence and mortality in China, 2009. J Thorac Dis. 2013; 5:19-26.

2. Gu H, Ding G, Zhang W, Liu C, Chen Y, Chen S, Jiang P. Replication study of PLCE1 and C20orf54 polymorphism and risk of esophageal cancer in a Chinese population. Mol Biol Rep. 2012; 39:9105-9111.

3. Pietas A, Schluns K, Marenholz I, Schafer BW, Heizmann CW, Petersen I. Molecular cloning and characterization of the human S100A14 gene encoding a novel member of the S100 family. Genomics. 2002; 79:513-522.

4. Chen $\mathrm{H}, \mathrm{Xu} \mathrm{C}$, Jin Q, Liu Z. S100 protein family in human cancer. Am J Cancer Res. 2014; 4:89-115.

5. Ehmsen S, Hansen LT, Bak M, Brasch-Andersen C, Ditzel HJ, Leth-Larsen R. S100A14 is a novel independent prognostic biomarker in the triple-negative breast cancer subtype. Int $\mathrm{J}$ Cancer. 2015; 137:2093-2103.

6. Chen H, Yuan Y, Zhang C, Luo A, Ding F, Ma J, Yang S, Tian Y, Tong T, Zhan Q, Liu Z. Involvement of S100A14 protein in cell invasion by affecting expression and function of matrix metalloproteinase (MMP)-2 via p53dependent transcriptional regulation. J Biol Chem. 2012; 287:17109-17119.

7. Wang X, Yang J, Qian J, Liu Z, Chen H, Cui Z. S100A14, a mediator of epithelial-mesenchymal transition, regulates proliferation, migration and invasion of human cervical cancer cells. Am J Cancer Res. 2015; 5:1484-1495.

8. Jin Q, Chen H, Luo A, Ding F, Liu Z. S100A14 stimulates cell proliferation and induces cell apoptosis at different concentrations via receptor for advanced glycation end products (RAGE). PLoS One. 2011; 6:e19375.

9. Sapkota D, Bruland O, Costea DE, Haugen H, Vasstrand EN, Ibrahim SO. S100A14 regulates the invasive potential of oral squamous cell carcinoma derived cell-lines in vitro by modulating expression of matrix metalloproteinases, MMP1 and MMP9. Eur J Cancer. 2011; 47:600-610.

10. Chen H, Yu D, Luo A, Tan W, Zhang C, Zhao D, Yang M, Liu J, Lin D, Liu Z. Functional role of S100A14 genetic variants and their association with esophageal squamous cell carcinoma. Cancer Res. 2009; 69:3451-3457. 
11. Herhaus L, Sapkota GP. The emerging roles of deubiquitylating enzymes (DUBs) in the TGFbeta and BMP pathways. Cell Signal. 2014; 26:2186-2192.

12. Hong S, Lim S, Li AG, Lee C, Lee YS, Lee EK, Park SH, Wang XJ, Kim SJ. Smad7 binds to the adaptors TAB2 and TAB3 to block recruitment of the kinase TAK 1 to the adaptor TRAF2. Nat Immunol. 2007; 8:504-513.

13. Yao K, Hua L, Wei L, Meng J, Hu J. Correlation Between CASC8, SMAD7 Polymorphisms and the Susceptibility to Colorectal Cancer: An Updated Meta-Analysis Based on GWAS Results. Medicine. 2015; 94:e1884.

14. Godiska R, Chantry D, Raport CJ, Sozzani S, Allavena P, Leviten D, Mantovani A, Gray PW. Human macrophagederived chemokine (MDC), a novel chemoattractant for monocytes, monocyte-derived dendritic cells, and natural killer cells. J Exp Med. 1997; 185:1595-1604.

15. Hirota T, Saeki H, Tomita K, Tanaka S, Ebe K, Sakashita M, Yamada T, Fujieda S, Miyatake A, Doi S, Enomoto T, Hizawa N, Sakamoto T, et al. Variants of C-C motif chemokine 22 (CCL22) are associated with susceptibility to atopic dermatitis: case-control studies. PloS one. 2011; 6:e26987.
16. Bertini I, Borsi V, Cerofolini L, Das Gupta S, Fragai M, Luchinat C. Solution structure and dynamics of human S100A14. J Biol Inorg Chem. 2013; 18:183-194.

17. Zhang Q, Zhu M, Cheng W, Xing R, Li W, Zhao M, Xu L, Li E, Luo G, Lu Y. Downregulation of $425 \mathrm{G}>$ a variant of calcium-binding protein S100A14 associated with poor differentiation and prognosis in gastric cancer. J Cancer Res Clin. 2015; 141:691-703.

18. Wei J, Zheng L, Liu S, Yin J, Wang L, Wang X, Shi Y, Shao A, Tang W, Ding G, Liu C, Chen S, Gu H. MiR-196a2 rs11614913 $\mathrm{T}>\mathrm{C}$ polymorphism and risk of esophageal cancer in a Chinese population. Hum Immunol. 2013; 74:1199-1205.

19. Chen ZJ, Zhao H, He L, Shi Y, Qin Y, Shi Y, Li Z, You L, Zhao J, Liu J, Liang X, Zhao X, Zhao J, et al. Genome-wide association study identifies susceptibility loci for polycystic ovary syndrome on chromosome 2p16.3, 2p21 and 9q33.3. Nat Genet. 2011; 43:55-59. 